Cómo citar este artículo en MLA: Motato, Hernando y Hugo Armando Arciniegas. "De Los idiotas a La gallina degollada: el encuentro con el horror". Escritos 28. 60 (2020): 1-14. doi: http://dx.doi.org/10.18566/escr.v28n60.a01

Fecha de recepción: 25.11 .2019

Fecha de aceptación: 30.03 .2020

\title{
De Los idiotas a La gallina degollada: el encuentro con el horror
}

\author{
From "Los idiotas" to "La gallina degollada": \\ a encounter with the horror
}

\author{
Hernando Motato $C^{1}$ \\ Hugo Armando Arciniegas ${ }^{2}$
}

\begin{abstract}
RESUMEN
En este artículo nos proponemos analizar, de manera comparativa, los cuentos Los idiotas, de Joseph Conrad, y La gallina degollada, de Horacio Quiroga, a partir de la propuesta del término encuentro; en este caso, del encuentro con el horror. Para este fin, retomamos las acciones clave que se cruzan en los dos relatos. Por razones de transparencia, evitamos el exceso de teorías referidas a relaciones intertextuales, si bien en su momento aludimos a un concepto teórico que estimamos clave: la parodia, de Bajtín. Nuestra intención, no obstante, es hacer énfasis en nuestra propia propuesta conceptual: la del encuentro. Nos interesa que el lector se enfrente él mismo con el cuento antecedente que genera el nacimiento del cuento sucesor, y reflexione, en consecuencia, sobre el proceso creativo, sobre la poética misma. Como eje de articulación de este artículo, destacamos cómo Conrad influye en Quiroga y cómo ambos escritores, en sus cuentos referidos, conciben el tema del horror a partir del motivo de los hermanos que sufren la degradación física y mental que genera tragedias en los jóvenes matrimonios.
\end{abstract}

Palabras clave: Encuentro; Horacio Quiroga; Joseph Conrad; Proceso creativo; Horror.

\begin{abstract}
In this article, we aim to carry out a comparative analysis of the short stories The Idiots, by Joseph Conrad, and $L a$ gallina degollada, by Horacio Quiroga, whereby we introduce the term conjunction; in this case, the conjunction of horror. To this end, we refer to the key actions that are common to the two stories. For reasons of transparency, we avoid the excess of theories regarding intertextual relations, although we allude to one key theoretical concept for this study: the parody, proposed by Bakhtin. Our purpose, however, is to emphasize our own conceptual
\end{abstract}

1 Magíster en Literatura por la Universidad Javeriana, Colombia. Profesor e investigador, Escuela de Idiomas, Universidad Industrial de Santander, Colombia. Grupo de investigación Glotta, línea de estudios: estudios literarios. Correo electrónico: mafecitamotato@gmail.com

2 Magíster en Estudios Avanzados en Literatura Española e Hispanoamericana por la Universidad de Barcelona, España. Catedrático e investigador, Escuela de Idiomas, Universidad Industrial de Santander, Colombia. Grupo de investigación Glotta, línea de estudios: estudios literarios. Correo electrónico: hugo.arciniegas@correo.uis.edu.co 
proposal: that of the conjunction. It is our intention that the readers face themselves with the antecedent story which gives birth to the succeeding story, and reflect on the creative process, on the poetics itself. As the axis of articulation of this article, we highlight the influence of Conrad on Quiroga, and how both writers, in the abovementioned stories, conceive the theme of horror based on the motif of the brothers who suffer physical and mental degradation, which trigger tragedies for the young couples.

Keywords: Conjunction; Horacio Quiroga; Joseph Conrad, Creative process; Horror.

\section{Vidas paralelas a partir de la aventura y el horror}

$\mathrm{P}$ artimos de una breve exposición de las vidas de Joseph Conrad y de Horacio Quiroga, que resulta indispensable en el despliegue de nuestro análisis. Quiroga asume formas semejantes o paralelas a la vida de Conrad, que constituyen los derroteros de un proceso creativo entendido como presencia e influencia de otros autores en la obra propia. Como el mismo Quiroga lo manifiesta en su decálogo: "Cree en un maestro -Poe, Maupassant, Kipling, Chéjov- como en Dios mismo" (“Decálogo", 29).

Por una parte, sobresale la vida aventurera, constante en ambos escritores, que influye en sus visiones de mundo. Por otra parte, los relatos de horror y la presencia de la muerte en su obra son productos de esas mismas experiencias. Lo anterior se sustenta en las lecturas que Quiroga hace de este escritor británico, en la medida en que encuentra en Conrad directrices para la configuración de su cuentística y, en especial, del cuento La gallina degollada.

En 1896 el periódico Savoy publica Los idiotas -“The Idiots"-, un relato que integra el volumen titulado Cuentos de inquietud -Tales of Unrest, en el original-, en el que también se publican los relatos Karain: un recuerdo, Una avanzada del progreso, La laguna y El regreso. Su autor, Joseph Conrad, un hombre protagonista de una intensa vida literaria y aventurera, nace el 3 de diciembre de 1857, en la actual Ucrania, y desde los 17 años se embarca y recorre el mundo durante 20 años. A los 21 años aprende inglés, lengua en la que escribe toda su obra, y su dominio le otorga la nacionalidad británica en 1884 .

A los 38 años abandona su vida citadina para consagrarse a los mares, especialmente asiáticos. Estas experiencias son el soporte de su actividad creativa. De tales experiencias, el británico escribe novelas de ambiente aventurero en lejanas y recónditas tierras, como las islas Malaya y Borneo: La locura de Almayer (1895), Lord Jim (1900), El corazón de las tinieblas (1902) y Victoria (1915), entre otras. Su vida está llena de experiencias reveladoras que le permiten adentrarse en el corazón de unos espacios que son vitales en su proceso de escritura, de los que se nutre para la creación de tramas y personajes complejos.

De igual modo, la trashumancia de Quiroga y la vida en Misiones colman la etapa creadora del uruguayo. El escritor se apropia de ese aire opresivo que resulta determinante en la fatalidad de sus personajes. A su vez, cobra valor la vivencia en medio de las dificultades que lo ponen en contacto con la realidad opuesta a ese pasado de opulencia en el que vivió su infancia. En relación con tales tópicos de su vida se encuentran algunos de sus cuentos, como Los inmigrantes, A la deriva, El alambre de púa, Los mensú y La gama ciega, entre otros. Más aún, esto devela la estrecha afinidad con su maestro Conrad, en cuanto reconoce cómo el destino ciñe su horizonte estético y les otorga unidad a los motivos de la selva. 
Para ilustrar lo anterior, nos remitimos a Pedro Orgambide, quien señala que este escritor uruguayo nace el 31 de diciembre, en Salta, y, al igual que Conrad, tiene una infancia llena de opulencia. Ambos pertenecieron a familias aristocráticas y, sin embargo, fatalmente empobrecidas, bien por las crisis económicas, bien por el despilfarro o la vida trágica (15). En Quiroga, la alcurnia, la riqueza y el bienvivir determinan su vida de dandi. Conrad explora los mares; Quiroga, la vida en la selva de Misiones. Ambos fueron rebeldes y tuvieron propósitos muy claros en su quehacer literario: narrar la vida cotidiana de sus personajes.

\section{Los idiotas y La gallina degollada}

El primer cuento objeto de este análisis, Los idiotas, trata de la vida atormentada de un joven matrimonio que desemboca en una tragedia familiar. Una tragedia que se relaciona directamente con el nacimiento de sus hijos "idiotas": un par de gemelos, una niña y un cuarto hijo, que, a los pocos días de nacidos, sufren fiebres que derivan en la enfermedad degenerativa o idiotez. Los padres no soportan este mal. El esposo se lanza de un puente y muere. Mas Susana, la esposa, en medio de una borrachera, grita que fue ella quien lo mató. La esposa, por su parte, enloquece luego de una vida de penurias sociales y mentales. "Allá va la madre de los idiotas", le gritan en la calle, y ella se suicida lanzándose a un abismo. Jean Pierre Bacadou es el nombre del marido, un afamado granjero de Ploumar. Susana, la esposa, es hija de una poderosa mujer, dueña de tierras, negocios y una mina de granito.

Con la llegada de un nuevo hijo aflora la esperanza de un hijo normal, pero poco a poco aparece de nuevo la tragedia. Nadie asume la responsabilidad genética de la tara. Jean Pierre culpa a su esposa de la idiotez, a causa del alcoholismo de su madre, madame Lavaille. Susana les endilga ese mal a las enfermedades de su suegro, un viejo agobiado por el reumatismo, y a su suegra, quien vivió sus últimos años postrada en una cama. Los idiotas quedan a la deriva, y solo atinan a salir por los caminos para ver pasar los carruajes. Un cochero oficia de narrador, cuenta a su pasajero la historia infortunada de esa familia y señala, paso a paso, a los idiotas que aparecen entre los zarzales de la vía.

En 1917 se publica el cuento La gallina degollada. En este, un joven matrimonio sufre la desgracia de tener cuatro hijos idiotas. Nace el primero, y a los dieciocho meses sufre una fiebre y luego la enfermedad degenerativa. Así nacen los demás niños, con igual padecimiento. Por último, nace la niña Bertita, que es la esperanza de ese joven matrimonio. Pasan los meses y la niña crece normalmente, lo que les devuelve la alegría a los padres: “¡Al fin una hija sana!”, exclaman.

\section{El encuentro}

En principio, puede parecer que el término encuentro, propio del oficio de lector, de la lectura placentera por sí misma, no tiene mucha afinidad con algunos conceptos de la teoría literaria, como la parodia, lo refractario del texto, el dialogismo, la intertextualidad o la literatura comparada, planteamientos útiles e indispensables para llevar a cabo análisis de este tipo -dos de los cuales, parodia e intertextualidad, comentaremos brevemente más adelante-. No obstante, sí se relaciona estrechamente con estos conceptos 
y establece un diálogo directo con ellos. Por encuentro entendemos el placer de hallar en una obra imágenes ya vistas en otras; el placer de encontrar cómo está contada la historia y cómo se desarrolla la trama en ambos textos: el antecedente y el sucesor. Nuestra intención a la hora de señalar este concepto es dejar en libertad al lector para que realice cualquier aproximación analítica comparativa, de acuerdo con su especialidad u orientación teórica, a los textos con los que se encuentre en su experiencia lectora. En lo que respecta a este artículo, nos referimos a los cuentos de nuestro análisis, así como a las respectivas reflexiones sobre el horror a partir del proceso creativo.

\section{El horror y el terror}

Establezcamos una necesaria distinción entre 'horror' y 'terror'. Para esto, nos remitimos al Diccionario de uso del español, de María Moliner. De su amplia definición de 'terror', sobresale la siguiente acepción: 'Impresión producida en una persona por algo catastrófico, sangriento o cruel' (66). Esto es, el terror se define como espanto, pánico o miedo. El horror es la manifestación externa que influye en el comportamiento del individuo, mientras que el terror es interno y afecta los sentidos. En el horror hay rastros del pasado y de las culpas morales y existenciales que están unidas a elementos incomprensibles o sobrenaturales que desencadenan tragedias.

Esta diferenciación no implica que haya distancias entre estos dos conceptos. Al contrario, hay una estrecha afinidad que conduce a lo fantástico. Freud asocia el horror con lo siniestro, sobre la base del sentimiento de lo extraño. Hay en esta apreciación freudiana una puesta en escena con lo secreto, lo oculto, lo incomprensible de ese sentimiento, de ese algo que no tiene una explicación lógica.

De ahí que el horror en los cuentos de Conrad y Quiroga sea una suerte de maldición a las jóvenes parejas: la condena siniestra de tener hijos idiotas. En ellos lo cotidiano del hogar se ensombrece con la anormalidad de los hijos. Entonces, ¿qué es lo oculto en este mal? Las discusiones de las parejas recaen en la tara familiar; los esposos se culpan entre sí. Podría decirse que estamos ante dos cuentos sofocleanos, pues allí condenan a las descendencias supuestas maldiciones en los linajes.

Vale la pena traer a cuento lo expuesto por José Antonio Pulido, quien hace una clasificación de los diferentes motivos del horror: psicológicos, con el ejemplo de La historia del endemoniado Pacheco, de Jan Potocki; de fantasmas, con ejemplos en La litera superior, de Francis Marlon Crawford y La diligencia fantasma, de Amelia Edwards; sobre posesiones demoniacas, con ejemplos en La mano encantada, de Gerard de Nerval; y de asesinatos atroces, con ejemplos en La gallina degollada, entre otros.

Los dos cuentos pueden enmarcarse en este último tipo de horror -si bien en Los idiotas no hay propiamente un asesinato atroz, sino un suicidio atroz-. En estos cuentos se entrecruzan situaciones grotescas, como el suicidio del esposo ante la presencia de su amada, en el cuento de Conrad, o la manera despiadada en la que los hermanos asesinan a su hermana, en el de Quiroga. La atmósfera de suspenso se extiende a medida que aparecen los idiotas en el camino, en el primer cuento, así como la mirada atenta de los niños ante el modo en que la empleada descuartiza la gallina, en el segundo. 


\section{Apreciaciones sobre el horror}

El escritor argentino Abelardo Castillo, en el liminar a la obra cuentística de Quiroga, menciona que: "el horror ante la muerte aparece tan nítido en su literatura y en sus actos como una rebeldía ante la fatalidad, y es su exorcismo" (xxvi). Se trata de la rebeldía del genio, del joven dandi que paseó por Francia en bicicleta, del exorcismo de sus penurias por las muertes fortuitas que lo rodearon siempre. Existe una asociación directa en la obra de Quiroga entre la muerte y algunos ribetes autobiográficos, fatales, alucinatorios, macabros. Esta relación estrecha entre la muerte y la vida es más clara en La gallina degollada, cuando los idiotas asumen el calificativo del horror al descuartizar a su hermana, hecho que se narra con naturalidad, con calma:

— ¡Suéltame! ¡Déjame! — gritó sacudiendo la pierna. Pero fue atraída.

-¡Mamá! ¡Ay, mamá, papá! —lloró imperiosamente. Trató aún de sujetarse del borde, pero sintióse arrancada y cayó.

— ¡Mamá! ¡Ay, ma!... - . No pudo gritar más. Uno de ellos le apretó el cuello, apartando los bucles como si fueran plumas, y otros la arrastraron de una sola pierna hasta la cocina, donde esa mañana se había desangrado la gallina, bien sujeta, arrancándole la vida, segundo por segundo. (95)

Allí aparece el horror, en la repetición calculada por los idiotas, quienes aprietan el cuello de Bertita, tal como la empleada lo hizo con la gallina, y la arrastran hacia la cocina y la despedazan en un ritual siniestro. En ellos no hay limitaciones humanas que impidan el poder siniestro y fascinante de la sangre. Las súplicas de la niña no son oídas; sus padres la han abandonado. A propósito de esta escena, Pulido plantea:

La gallina degollada es un relato donde el dolor y el placer se combinan en una impresión única. De los motivos que deberían provocar desagrado -la muerte de la niña por los cuatro hermanos idiotas- brota un nuevo sentido de agrado ante la tortura. (106)

El placer que encuentran los niños en mutilar el cuerpo de la niña, el crimen como una posibilidad de juego en medio de la idiotez constituyen el horror entre el regocijo y la tragedia. En esta misma línea, el crítico Emir Rodríguez Monegal plantea, en un ensayo "Horacio Quiroga: vida y creación", que el tema de la muerte en los cuentos del uruguayo pasa por la crueldad, el sadismo y el sufrimiento:

Es claro que también hay crueldad en sus cuentos. Incluso hay relatos de esplendorosa crueldad. Hay relatos de horror. Quizá el más típico es "La gallina degollada" (julio 10, 1909). Este cuento, que por su difusión ha contribuido a configurar la imagen de un Quiroga sádico del sufrimiento, presenta, como es bien sabido, la historia de una niña asesinada por sus cuatro hermanos idiotas. Del examen atento, surge, sin embargo, el recato estilístico del manejo del horror, un auténtico pudor expresivo. (89)

Milagros Ezquerro, por su parte, confiere al horror en el cuento de Quiroga un ambiente de maldición: la de la tara hereditaria de los esposos:

El terrible relato de "La gallina degollada" toma el aspecto de una maldición que pesa sobre el amor de una pareja que tiene sucesivamente cuatro hijos idiotas y luego una niña encantadora. La hermanita será degollada (por los cuatro idiotas) de la misma manera que la gallina fue degollada, la mañana anterior, 
por la criada. La violencia del amor, envenenado por el amor por la maldición recurrente, es el equivalente exacto del horror de la situación, descrita con minuciosa perversidad. (138)

Maldición es la palabra que aproxima el cuento de Quiroga a la tragedia griega, en especial a la de Sófocles. Es la violencia encarnada en la degradación mental de los hermanos y en la paradoja del amor sumido en el fracaso, la culpabilidad y la desgracia familiar. Ezguerro acierta al conferirle un peso enorme a la tara y a cómo esta incide en la tragedia familiar, pues en el cuento de Quiroga -así como también en el de Conrad- este mal suscita el distanciamiento entre los esposos y precipita la muerte violenta.

Crueldad, horror y fatalidad son expresiones clave en la apropiación que hace Quiroga del cuento antecedente, Los idiotas. Tal como apuntamos antes, el cuento empieza con la narración que hace un cochero a su pasajero. Él le señala la presencia de un idiota a la vera del camino entre Treguier y Kervanda, y en tanto avanzan por el sendero, aparecen los otros tres idiotas entre los árboles y la maleza.

—iAh! Ahí hay otro — dijo el hombre, con cierta satisfacción en su tono, como si hubiera visto algo que esperaba.

Había otro. Este estaba en medio del camino, bajo el ardor del sol, al extremo de su corta sombra. Estaba de pie, con cada mano embutida en la manga opuesta de su larga chaqueta y la cabeza hundida entre los hombros, recogido sobre sí mismo entre las oleadas de calor. Visto a cierta distancia parecía una persona que sufriera un intenso frío.

—Son gemelos -explicó el cochero. (58)

Esta es la representación de una culpa, de una ascendencia depravada y tarada. El cochero cuenta lo que pasa con estos niños abandonados por unos padres que no soportaron los señalamientos de sus vecinos: "En la estrecha senda de los carros recogedores de algas, cuatro hombres llevaban tierra adentro el cadáver de Susana en una carretilla" (89). Se anuncia allí el final suscitado por la degradación de la esposa alcohólica, que es arrastrada como un alga más en una carretilla. Ya no es más el personaje encantador que rinde a Jean Pierre y lo llena de felicidad al comienzo del matrimonio.

A lo anterior se agregan las escenas de crueldad que soporta Susana, quien, además de sufrir las burlas de sus vecinos, sufre también las acusaciones de su esposo por la tara de sus hijos y, por último, presencia el suicidio de su esposo.

- ¿A dónde vas? — gritó él, ásperamente.

— ¡A casa! —respondió ella, mirándole intensamente. Él saltó con torpe zancada, a otra piedra, y volvió a detenerse, balanceándose. Luego dijo:

- ¡Ajá! Bueno, voy contigo. Es lo menos que puedo hacer. jJa, ja, ja!

Ella le miró hasta que le pareció que sus ojos se convertían en brasas que ardían en lo más profundo de su cerebro; y, sin embargo, tenía un miedo mortal de reconocer aquellas facciones tan familiares. Allá abajo, el mar chasqueaba suavemente contra la roca, en un chapoteo continuo y suave.

El hombre dijo avanzando otro paso:

-Vengo por ti. ¿Qué te imaginas?

Ella se puso a temblar. ¡Por ella! No había escapatoria, no había paz, ni esperanza. Miró desesperada a su alrededor. Súbitamente toda la costa envuelta en sombras, las isletas indistintas, el cielo, giraron dos veces, y luego se detuvieron. Cerró los ojos y gritó:

$-\_$Es que no puedes esperar hasta que esté muerta? (88) 
El esposo cree que el mal es el resultado de las enfermedades de la esposa; es incapaz de asumir el dolor y el fracaso matrimonial. Se deduce que la historia está focalizada en las penas y el sufrimiento de Susana. De ahí que en Los idiotas haya una descripción panorámica de los niños. Ellos, inocentes, pasean por el campo su mal, y con este la vergüenza y el escarnio de su madre. Mediante una descripción pausada, con la cual se configura un ritmo lento de la trama, se hace más intenso el motivo del horror. El narrador presenta a los idiotas en el camino y luego se interna en los padecimientos de los padres. Por tanto, la locura, el licor y el suicidio determinan las escenas del horror en este cuento.

Estos actos demenciales generan, en Susana, desconcierto, incertidumbre, fracaso y, por último, locura. Para ella no hay alternativa: la locura es su mejor aliada, y en ese estado muere. Este es el final del cuento, pero entre el encuentro de los idiotas y la llegada al pueblo se intercala otra escena narrativa: el regreso de Jean Pierre del servicio militar. Llega a la finca de sus viejos padres y la encuentra en el más absoluto abandono, ya que el padre no tiene la energía de otros tiempos, y los mozos no le obedecen. También halla a su madre sumida en la cama y a unas criadas desinteresadas de sus oficios.

En este otro escenario de la historia la prosperidad ilumina el pensamiento del hijo que ha regresado del ejército. "Hay que cambiar todo esto, se dijo. Habló del asunto con su padre cierto atardecer" (Conrad 60). Unos personajes nacidos y criados en el campo, especialmente desde la mentalidad masculina, tienen la idea de que el hombre debe tener una esposa que le ayude en las labores y tenga hijos para la labranza y prosperidad de la tierra. Por esta razón se casa Jean Pierre.

A la madre le gustó la nuera. Jean Pierre entró impetuosamente en el patio con el carro de ballestas de dos ruedas. El caballo gris galopaba torpemente, y la recién casada y su marido, sentados uno junto a otro, se bamboleaban hacia atrás y hacia adelante con el movimiento rebotante de los ejes, de manera regular y brusca. En el camino, los invitados a la boda, que habían quedado atrás, se dispersaban en parejas y en grupos. (61)

Se conviene la boda con la joven Susana. Con el matrimonio las cosas cambian en la finca. El narrador no describe el proceso de enamoramiento de Jean Pierre, pero sí focaliza su atención en la vida de la pareja. El narrador se concentra también en la forma en que Jean Pierre trabaja la tierra, en el nacimiento de los hijos y en la triste constatación de que a determinada edad se vuelven idiotas.

En otro orden de ideas, se ubica el punto de encuentro con el texto de Quiroga: la degradación mental de los hijos: "Tenían la lengua entre los labios, los ojos estúpidos y volvían la cabeza con la boca abierta" (89). Este es el comienzo de la desgracia, la puesta en orden del cuento nuevo a partir de su antecesor. El narrador no solo resalta la degradación física de los hermanos, sino que anticipa el mal de la familia.

El comienzo de La gallina degollada también es revelador: "Todo el día, sentados en el patio en un banco, estaban los cuatro hijos idiotas del matrimonio Mazzini-Ferraz" (89). De esta misma manera, con la presentación de los personajes, aparece la primera apropiación del discurso literario y la trama del cuento de Conrad. Quiroga, no obstante, es más atento que Conrad en la descripción de los niños. Su narración se enfoca en el horror que producen las facciones de los rostros desencajados de estos niños.

Este encuentro deja en evidencia la apropiación que hace Quiroga del cuento de Conrad. En términos teóricos, dichos encuentros en el trabajo de escritura se denominan también parodia, en términos bajtinianos, o intertextualidad, en los de Genette. Lo paródico define el quehacer escritural o creativo; 
es la apropiación o imitación de lo ya dado en otro relato. Es también el seguimiento al trabajo de escritura, la representación del discurso referido con intenciones similares a las suyas. Cuando Bajtín alude al discurso ajeno plantea también el trabajo de aprehensión del texto fuente. Hay un texto predecesor que sirve de referencia en el acto creativo, y este requiere unas transformaciones que dan un vuelco al texto original.

Las historias que aquí nos competen corren paralelas. En el cuento de Quiroga aparece el matrimonio joven que tiene unos hijos que, en una primera etapa de su vida (dieciocho meses de nacidos), llenan de alegría ese hogar pero, justo después, aparecen la fiebre y el estado de postración física e idiotez. Este es el horror encarnado en la ilusión de tener un hijo sano. Sobre este planteamiento, apelamos de nuevo a las reflexiones de Pulido, quien afirma:

... sus relatos [los de Quiroga] son de una esplendorosa crueldad y quizá el más típico de ello sea 'La gallina degollada’. En el mismo se ofrece la historia de una niña descuartizada por sus cuatro hermanos idiotas, donde se revive el verdadero manejo estilístico del motivo del horror. (104)

En Los idiotas hay un espacio ficcional: el camino, sitio de encuentro de los idiotas. Con esta escena sabemos después que han sido abandonados por sus padres y criados por unos abuelos desvalidos. El camino y la exposición al aire libre de los hermanos idiotas hacen más intenso el horror, puesto que su estado remite a una tragedia, a un estado de locura y a una exposición de unos niños a la crueldad y a la burla.

$\mathrm{Al}$ respecto del horror, la profesora Francoise Duvignaud, en El cuerpo del horror, define el 'horror' como la presencia deformada de los cuerpos, bien sea por la tortura, bien sea por las deformaciones genéticas. Por tanto, en ambos cuentos el horror se centra, en primera instancia, en las deformaciones físicas y mentales de los niños. Duvignaud expone posteriormente que el horror está asociado con el miedo, y "ese horror se vuelve insidioso, interior, equívoco. Extrañeza que hace a la muerte todavía más insoportable de lo que nunca fue en todo el transcurso de la historia” (16).

Lo insidioso del horror es el nacimiento de los idiotas, la presencia ante el cochero, en el cuento de Conrad, y la mirada atenta de los idiotas en la forma en que la empleada descuartiza la gallina y cómo ellos imitan esa muerte con su hermanita, en el de Quiroga. Tanto en el cuento de Conrad como en el de Quiroga los narradores insinúan una luz de esperanza en los padres, ya que, a medida que los niños crecen, la insidia del horror toma fuerza, y en ese sentido se interioriza el dolor y el fracaso de los padres. La muerte de los padres es la alternativa a la tragedia familiar en Los idiotas; en La gallina degollada, la tragedia de cómo los idiotas matan a la hermanita.

\section{El encuentro y la decodificación creativa}

El encuentro en los dos cuentos que analizamos ponen de manifiesto el proceso creativo; cómo hay huellas narrativas que develan las transformaciones en el nuevo cuento. Existe una decodificación creativa, que implica descubrir ese texto que da origen a uno nuevo y que requiere trabajo intenso por parte del escritor: la configuración de los personajes, la relación espacio-personaje y el desarrollo de la trama. 
Lo anterior exige profundización en el texto, y con ello se logra que ambos textos se recontextualicen en la dimensión cultural y social. Conrad describe los espacios que ocupan los idiotas -el camino y los breñales-, mientras Quiroga describe las facciones y actitudes de los niños. Por ejemplo, llama la atención que los niños idiotas repiten actos que ven u oyen, como la imitación del tranvía. Al final del cuento contemplan atentamente cómo la empleada mata a la gallina, y repiten esa escena con la hermana.

Otras veces, alineados en el banco, zumbaban horas enteras, imitando el tranvía eléctrico. Los ruidos fuertes sacudían asimismo su inercia, y corrían entonces, mordiéndose la lengua y mugiendo alrededor del patio. Pero casi siempre estaban apagados en un sombrío letargo de idiotismo, y pasaban todo el día sentados en un banco, con las piernas colgantes y quietas, empapando de glutinosa saliva el pantalón. (89)

La huella de recepción activa es el matrimonio que tiene hijos idiotas. Quiroga muestra cómo actúan los idiotas, mientras Conrad centra su atención en el drama de sus padres. Aquí el trabajo decodificador consiste en el traslape o superposición de acontecimientos narrativos. Esto es, el abandono de los niños. La culpa tiene semejanzas: en ambos cuentos los esposos recriminan su ascendencia, y esta es parte de la culpa. Por consiguiente, la palabra refractada -en palabras de Bajtín- es 'idiota', y con base en ella Quiroga construye el conflicto de su propio cuento.

El punto de afinidad entre estos cuentos define el conocimiento del quehacer del escritor, el saber qué hacer con las influencias o lecturas, o el canon determinante en la formación del escritor y los ánimos o inquietudes presentes en su visión de mundo. En este sentido, planteamos que gran parte de la obra de Conrad, al igual que la de Quiroga, está inspirada en sus experiencias como marinero y viajero, como hemos apuntado ya.

En Conrad la aventura, la locura y el horror se convierten en receptáculos para la presentación de unos personajes con virtudes y sus flaquezas. Esta dimensión psicológica del hombre, se diría para una aproximación más profunda a su obra, queda relegada a un segundo plano para mostrarnos el ambiente épico de sus personajes, tal como ocurre con La locura de Almayer, su primera novela. Esta novela da cuenta del desdichado Almayer, un holandés afincado en una remota isla de Borneo, cuyos reiterados fracasos económicos nos hacen recordar la vida llena de fracasos de Horacio Quiroga. Es, por tanto, en esta dimensión épica que sus personajes se enmarcan en los sufrimientos, en el enfrentamiento con la naturaleza, el peligro y el horror que ello implica, y que nos permite hermanarlo con Quiroga ${ }^{3}$.

Una pequeña digresión que ilumina la génesis de este texto crítico: la idea de este artículo nace de un libro iluminador sobre la vida de Quiroga y sus relaciones de amistad con Ezequiel Martínez Estrada. Nos referimos a El hermano Quiroga. Allí se encuentran las pasiones de Quiroga por sus autores preferidos. Pues bien, se da a conocer una magnífica facultad del escritor: la desmedida memoria con la cual aprende los relatos, con una pasmosa fidelidad a sus maestros. Aún más, se devela la presencia de escritores de vida aventurera en su quehacer estético, como Jack London, Bret Harte y Joseph Conrad. Al respecto, Martínez Estrada plantea:

3 Cuando Los idiotas, de Conrad, aparece publicado en 1896, Quiroga contaba apenas con veinte años, pero ya había iniciado su vida literaria con sus primeros poemas y cuentos, que luego publicaría con el título de Los arrecifes de coral. 
Así de Pan, de Hamsun, y de El colono de Malata, de Conrad, que prefería a todas las otras novelas, de las que recordaba situaciones y hasta diálogos, cuya exactitud corroboraba yo cada vez, pues me obligaba a releer las obras. Recortaba siempre lo importante de la masa multiforme del texto. Era infalible en el acierto fundamental y en la valoración de los méritos que distinguen a un autor de genio de otro de mediano talento y mucha habilidad. (71)

Pues bien, lo anterior confirma que Quiroga es un gran conocedor de la obra de Conrad, y que el tema de la locura y la muerte en algunos de sus cuentos pueden provenir de la presencia e influencia de sus lecturas. Con Los idiotas aparecen los siguientes cuadros narrativos que luego se difuminan en la historia de La gallina degollada.

En primera instancia, está la historia de los hermanos idiotas y del nacimiento de su hermana. En Los idiotas ella sufre la degradación mental, mientras que en La gallina degollada Berta es normal, pero es sacrificada como una gallina por sus hermanos. Quizás la culpa en el cuento de Conrad se debe a que el padre de Jean Pierre muere sumido por el reumatismo. Asimismo, ocurre a los niños idiotas: es una especie de castigo por ese comportamiento antirreligioso manifiesto tanto en el padre como en el hijo. Ambos odian a los curas, a quienes llaman "cuervos".

El canto de los ruiseñores golpeaba en ambos lados contra los altos muros de la iglesia, y rebotaba entre cruces de piedra y losas sepulcrales planas que tenían grabadas palabras de esperanza y de dolor.

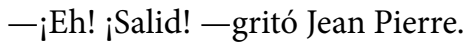

Los ruiseñores dejaron de cantar.

— ¿Nadie? — prosiguió Jean Pierre-. Nadie ahí. Una estafa de los cuervos. Esto es lo que es. Nadie en ninguna parte. Desprecio esto. Allez, houp! (72)

Esta es la voz desafiante ante la inclemencia del castigo y las desgracias de sus hijos idiotas. 'Nadie' es la negación a la fe, la incredulidad ante un posible e inexplicable milagro. Es la voz del desconsuelo. En lo que respecta a la madre de Susana, madame Levaille, se inclina a la bebida con cierta expresión demencial:

Madame Levaille volvió a coger la botella y dijo tranquilamente:

-Hola, hija mía. ¡Qué aspecto tienes!

El cuello de la botella tintineó en el borde del vaso, porque la anciana estaba sobresaltada, y se le había cruzado por la mente la idea de que la granja se había incendiado. (76)

De acuerdo con lo anterior, el cuento de Conrad presenta un cuadro clínico bastante traumático. Susana se suicida, pero en las alucinaciones deja la sensación de que ella mató a su esposo:

— ¿Sabe Jean dónde estás? ¿Dónde está Jean?

Susana pronunció con dificultad:

-Él, sabe... Está muerto.

—¿Qué? — gritó la anciana. Se acercó más a su hija, y mirándola atentamente, repitió tres veces:

—¿Qué es lo que dices? ¿Qué es lo que dices? ¿Qué es lo que dices? (78)

En cuanto al padre de Susana, es preciso señalar que murió loco. Esa tara la hereda su hija y con ello intensifica el dolor y el sufrimiento de su esposo, un miembro de la nobleza decadente y propietario de una de las granjas más grandes del poblado. 
Susana pronunció algunas palabras incomprensibles, mirando a la mesa. La anciana se enlazó las manos sobre la cabeza, las dejó caer, y se quedó mirando a su hija con expresión de desconsuelo. Su marido se "había puesto mal de la cabeza" unos años antes de morir, y ahora empezaba a sospechar que su hija se volvía loca. (77-78)

Lo anterior posibilita esta deducción: la presencia de la locura y la tragedia de esa familia da cuenta del derrumbe de una estirpe afincada en el poder terrateniente y en el conflicto de poder con la Iglesia. De este modo se comprende la postura anticlerical de los Bacadou. Cierra la tragedia de esta familia el suicidio de Susana: “- ¡Susana!, te vas a matar por ahí. La piedra había dado su último salto en las tinieblas, y ahora no oía nada” (82).

Los hijos idiotas, la locura de Susana, el asesinato o suicidio de Jean Pierre y el anticlericalismo son las escenas narrativas determinantes de esas voces en el cuento que dejan al trasluz el descontrol de la sinrazón, de la preocupación por lo verosímil, en la medida en que penetra en los paisajes inaccesibles de la reflexión racional. "Cierto día le dijo a su mujer: - A ver qué puede hacer tu Dios por nosotros. Ve a rezar en algunas misas" (69). La idiotez no es más que el modelo para descifrar la complejidad del cuento definida en la unidad de acción y el efecto del final.

Aquí surge un interrogante en la lectura del cuento: ¿cuál es el objetivo y sentido del cochero y del narrador al ver a los idiotas? Nada hasta aquí nos dice o explica un porqué, pero a medida que se avanza en la lectura se devela la actitud censurante de estos, puesto que el padre de los idiotas fue un hombre díscolo, descreído de la religión. Nunca fue a misa, y cuando cae en esta desgracia familiar, reta la presencia de Dios, aunque luego se arrepiente y establece buenas relaciones con el pastor

Ahora bien, los idiotas, punto de encuadre con La gallina degollada, son el pretexto o caja de resonancia para que el cuento de Quiroga sea concebido como receptor; pero existe algo más en el efecto de lo macabro: el manejo de la historia de un matrimonio fracasado a causa de la idiotez de sus hijos. Al respecto, Quiroga no se concentra en el núcleo de este relato, la tara, sino en la escisión para definir la estructura dual de la forma del cuento: la muerte de la niña. Y aquí cobra fuerza el tema del horror. Lo anterior, en primera instancia, define la forma en que la narración empieza precisamente con la presentación de los cuatro niños idiotas: “Todo el día, sentados en el patio en un banco, estaban los cuatro hijos idiotas del matrimonio Mazan-Ferraz. Tenían la lengua entre los labios, los ojos estúpidos y volvían la cabeza con la boca abierta" (89).

De tal manera, los idiotas de La gallina degollada remiten a un único sentido: el mal, el flagelo de la desgracia, la degradación física y mental de unos niños. Este motivo propicia el encuentro: el mal hereditario que aparece en ambos cuentos. En esta dimensión narrativa, los idiotas en La gallina degollada sostienen una ambivalencia discursiva, lo que de nuevo nos remite a Bajtín:

El mismo hecho de la existencia de los discursos doblemente orientados, que incluyen como aspecto necesario la relación con el enunciado ajeno, nos enfrenta a la necesidad de ofrecer su clasificación completa y exhaustiva desde el punto de este nuevo principio, que no se toma en cuenta la estilística, la lexicografía o la semántica. (343)

Así pues, tenemos que los idiotas representan la enfermedad mental. Los idiotas aparecen desde el comienzo de ambos cuentos. En Conrad son expuestos a la mirada del cochero, y luego aparece el traslape 
narrativo con el cual se remonta al pasado de los padres. Posteriormente, aparece la discordia porque cada uno de los esposos endilga la tara y la culpabilidad desde la mirada del otro: "Jean Pierre, ebrio, murmuraba rabiosamente, y rezongaba contra la maldita mujer que no era capaz de tener hijos como los de la demás gente. Susana, sujetándose contra los erráticos traqueteos del carro, fingía no oír" (71). La culpa, según lo anterior, es de Susana, un personaje que asume en silencio la palabra cargada de rabia. Es ella quien da vida a unos idiotas, mientras el esposo no reconoce la culpa en esa descendencia con taras. Esta misma situación se presenta en La gallina degollada. La culpa se le otorga a la esposa como una especie de condena a la mujer, expresión de un pensamiento machista.

- ¿Qué! ¿Qué dijiste?...

- ¡Nada!

— ¡Sí, te oí algo! Mira: ¡no sé lo que dijiste; pero te juro que prefiero cualquier cosa a tener un padre como el que has tenido tú!

Mazzini se puso pálido.

— ¡Al fin! —murmuró con los dientes apretados. — ¡Al fin, víbora, has dicho lo que querías!

- ¡Sí, víbora, sí! ¡Pero yo he tenido padres sanos! ¿Oyes?, ¡sanos! ¡Mi padre no ha muerto de delirio! ¡Yo

hubiera tenido hijos sanos como los de todo el mundo! ¡Esos hijos son tuyos, los cuatro tuyos! (93)

La escena de culpabilidad es refractaria a la estilización del horror. Ya en esta cita del cuento de Quiroga la esposa tiene voz, como se deja ver en la respuesta con la que acusa a la ascendencia de su esposo: la locura. Pero en la medida que él toma la palabra se desencaja y profiere palabras ofensivas con las cuales da cuenta de su incapacidad de argumentación.

El efecto de la descripción -idiotas, lengua entre labios y la boca abierta- permite el logro del núcleo del cuento. Tal como sucede en el cuento de Conrad, el orden de la narración no afecta el sentido expreso, y de una vez ambas historias se ponen en contacto. La semántica del cuento puede, por su mismo carácter, interpretarse en un sentido más amplio: el de la presencia de los conflictos internos de la familia y el peso de la tara desde la culpa genética. Lo anterior remite, en el sistema dialógico bajtiniano, a la estilización, que consiste en que el discurso referido se oriente al encuentro con el otro discurso, con el cual convergen en arrancar del original las partes indispensables o clave para el desarrollo de la historia.

Con Los idiotas aparece el siguiente cuadro narrativo que luego se difumina en la historia de La gallina degollada. Tal parece que el narrador y el cochero cumplieron su cometido, el de familiarizarnos con los cuatro idiotas.

Una niña nació al cabo de cosa de un año de esto. Una niña. Jean Pierre se enteró en los campos, y la noticia le trastornó tanto que se sentó en el muro del campo y se quedó allí hasta el anochecer, en vez de ir a casa como le habían pedido. Una niña. Se sentía medio estafado (70).

La misma situación se da en La gallina degollada. Se suman cinco hermanos, una pareja de mellizos, dos hermanos más y una niña sin enfermedades, Bertita. En este sentido, la muerte, concebida desde el horror, cumple la función mediadora entre ambos cuentos. Cobra valor la imitación y función creadora, la cual consiste en una interpretación de la historia y en el hecho de ambientarla en un espacio propicio: 
la selva. Mientras que en Los idiotas el nacimiento de la hija genera desazón y desesperanza; en el cuento de Quiroga se celebra con alegría y esperanza el nacimiento de un hijo sano, que es lo que los esposos deseaban.

En el nivel de su estructura formal, el cuento de Quiroga es la articulación de una síntesis, una incorporación de un texto en un segundo plano y un encuadre de lo viejo con lo nuevo. Pero este desdoblamiento no funciona más que para marcar la diferencia entre el cuento generador del otro cuento y la capacidad de asimilación y renovación en el nuevo. Una vez se reafirma la cuentística de Quiroga desde el ámbito del horror, el miedo y la fatalidad, comprobamos que estos aspectos del cuento de Quiroga son expresiones de lo que él afirma en su "Decálogo del perfecto cuentista": "Cree en un maestro -Poe, Maupassant, Kipling, Chéjov- como en Dios mismo" ("Decálogo”, 29). El encuentro entre Conrad y Quiroga no es más que otra prueba del reconocimiento a los maestros que han formado al uruguayo, que le han aportado técnicas para su labor como escritor.

\section{Conclusiones}

1. El análisis de La gallina degollada, desde la perspectiva de la comparación o intertextualidad con el cuento de Conrad, devela el oficio de escritura creativa, no solo de Quiroga, sino de los grandes escritores, pues en dicha labor hay un afán de pesquisa o rastreo para el desarrollo de la propuesta ficcional. En términos teóricos bien puede llamarse la angustia de las influencias, o sea, ese proceso liberador de un texto en la conciencia del escritor y la proyección de imágenes, metáforas y visiones en el nuevo texto ficticio. No solo Conrad forma parte de estos autores que influyen a Quiroga. También influye, por ejemplo, Edgar Allan Poe, lo que resulta evidente en el tratamiento de la muerte y de lo escabroso de ella. El ambiente de terror se manifiesta en los ámbitos de la selva, como también en el desarrollo de la tragedia.

2. La propuesta del término encuentro parte del placer de la lectura y del oficio de lector. Cuando el lector se enfrenta a una obra, y en la medida que avanza en su oficio de lector, aparecen imágenes ya vistas en otra obra. Entonces surge el placer de encontrar cómo está contada la historia y cómo se desarrolla la trama en ambos relatos. Por ejemplo, leemos El almohadón de plumas y nos parece que el horror está patente en la muerte de la muchacha; no obstante, leemos más tarde Vania colgada al cuello y El amor de un contrabajo, de Antón Chéjov, y en ellos vemos cómo el humor, aun en medio de la muerte, se sugiere de manera magistral. Entonces regresamos a El almohadón de plumas y percibimos por fin una dosis de humor en la ingenuidad de la joven recién casada. Ella evoca la noche de bodas, pero no se da cuenta de qué hay en la almohada, en tanto la empleada sentencia de manera elemental la causa de la muerte. Entonces hablamos de un encuentro entre Quiroga y Chéjov.

3. Hasta aquí se han revelado algunas aproximaciones al cuento de Conrad desde la dimensión del horror vista en el contexto de la creación. Hemos liberado el análisis de concepciones teóricas, no como una actitud descolonizadora de las teorías -tal como lo propuso Antonio Cornejo Polar, con base en la polaridad de nuestra cultura mestiza y en la apropiación de heterogeneidad conceptual y analítica-, sino en el afán de que el lector -y aun el lector-escritor- perciba el quehacer y oficio del escritor, así como la manera en que se apropia de un texto anterior para la génesis de uno nuevo. 


\section{Referencias}

Bajtín, Mijaíl. Problemas de la poética de Dostoievski (T. Bubnova y J. Alcázar, Trads). México: Fondo de Cultura Económica, 2012.

Castillo, Abelardo. "Liminar: Horacio Quiroga”. Quiroga, Horacio. Todos los cuentos. Madrid: Colección Archivos, 1993.

Conrad, Joseph. Relatos de terror (A. A. D’Amonville, Trad.). México: Editorial Fontamara, 1988.

Duvignaud, Francoise. El cuerpo del horror (M. Lara, Trad.). México: Fondo de Cultura Económica, 1987.

Ezquerro, Milagros. "Los temas y la escritura quiroguianos". Quiroga, Horacio. Todos los cuentos. Madrid: Colección Archivos, 1993.

Martínez Estrada, Ezequiel. El hermano Quiroga. Cartas de Quiroga a Martínez. Caracas: Editorial Ayacucho, 1985.

Orgambide, Pedro G. Horacio Quiroga. El hombre y su obra. Buenos Aires: Editorial Stilcograf, 1954.

Pulido Z., José Antonio. El horror como motivo en el cuento latinoamericano y del Caribe. Caracas: Fundación editorial El Perro y la Rana, 2009.

Quiroga, Horacio. Todos los cuentos. Madrid: Colección Archivos, 1993.

Quiroga, Horacio. "Decálogo del perfecto cuentista". Teorías de los cuentistas, vol. 1. Ed. Lauro Zavala (ed.). México, Universidad Nacional Autónoma de México, 1993.

Rodríguez Monegal, Emir. "Horacio Quiroga: vida y creación”. Narradores de esta América. Caracas, Alfadil ediciones, 1993. 